sary and sufficient condition that the quadratic (9) be satisfied by any two values of $t_{2}$ is expressed by equating to zero the coefficient of each power of $t_{2}$ in (9). The determinant of these three equations equated to zero is

$$
\left|\begin{array}{ccc}
3|a b x| & 3|a c x| & |a d x| \\
3|a c x| & |a d x|+9|b c x| & 3|b d x| \\
|a d x| & 3|b d x| & 3|c d x|
\end{array}\right|=0,
$$

and this is the equation of the $R^{3}$ as the locus of a point $x_{i}$ which coincides with a point of the $R^{3}$.

The method of finding the equation of the line determined by the points of the $R^{n}$ whose parameters are $t_{1}$ and $t_{2}$ requires no formal statement. If this equation is represented symbolically by

$$
n|a b x| t_{1}{ }^{n-1} t_{2}{ }^{n-1} \cdots=0,
$$

by arranging (11) as a binary $(n-1)$-ic in $t_{2}$ and equating the coefficients of the powers of $t_{2}$ to zero $n$ equations are obtained, and the determinant of these equations equated to zero is the equation of the $R^{n}$.

Pennsylvania State College, November, 1915.

\title{
THE PHYSICIST J. B. PORTA AS A GEOMETER.
}

BY PROFESSOR GINO LORIA.*

IN his remarkable and entertaining Budget of Paradoxes, of which a new edition has just been published under the editorship of David Eugene Smith, Professor De Morgan speaks of the work entitled "Io. Baptista Portae Neapolitani Elementorum curvilineorum Libri tres. In quibus altera de Geometriae parte restituta, agitur de Circuli Quadratura (Romæ, MDCX)," in the following words: "This is a ridiculous attempt, which defies description, except that it is all about lunules."

Such a scornful judgment forms an evident contrast to the opinion expressed by M. Chasles, who in his Apercu Historique ${ }^{+}$

* Translated from the author's manuscript by Madelaine A. Batta.

+ Second edition, Paris, 1875, p. 216. 
speaks of Porta with respect, placing him among the geometers who used the method of geometric transformation which causes the ordinates of the points of a figure to grow proportionally. To the support of his appreciation this great geometer refers at the foot of the page to "Elementa Curvilinea, Book I," giving neither date nor place of publication.

Considering Chasles's scholarly methods, this leads one to believe that he did not have the original work before him when he wrote these words. At any rate it is impossible to tell which of the three editions mentioned by Riccardi* he had a chance to consult. Of these editions the first appeared in 1601 as an appendix to the Pneumaticorum Libri tres, the second bears the date, Naples, 1609, and the third is the edition known to De Morgan and which I also have examined.

Four years after the first publication of Chasles's opinion (1837) another celebrated historian, Libri, declared" that "The Elements of Curves includes an essay on the quadrature of the circle and shows that the author was not a genius in mathematics; for, besides errors, there are many insignificant matters mentioned in the work."

This judgment is fundamentally in accord with that of Montucla $\ddagger$. It is less severe than that of De Morgan and, according to my idea, more true and more exact. To justify my point of view I propose to give an analysis of the opuscula of my fellow countryman, which I shall try to make more faithful to the facts.

This work comprises 96 pages, $15 \times 20.5 \mathrm{~cm}$., and is composed of three "books" which are not at all closely connected. In the first book the author reviews the method by which it is possible to construct a circle which shall be a multiple of a given circle, or which shall be the sum or the difference of two given circles, or to transform two unequal circles into two equal circles which together shall be equal to the two given circles, etc. After that he turns to analogous questions relating to the ellipse. The constructions given by Porta are based on the known expressions for the area of a circle and the area of an ellipse, and on the applications of the theorems

\footnotetext{
* Biblioteca Matematica Italiana, Part 1, col. 380.

+ Histoire des Sciences mathématiques en Italie, Tome IV, Paris, 1841, p. 138.

\pm Histoire des Recherches sur la Quadrature du Cercle, second edition, Paris, 1831, p. 203.
} 
of the first few books of Euclid's geometry. We regard the questions relating to the circle as having a general corollary, that is to say, that "The circles of a plane form a class of geometric magnitudes." Furthermore they prove that it is possible to operate on circular areas by means of arithmetic operations even before these areas are calculated. From this point of view, the first book of the Elementorum Curvilineorum Libri tres might be of service even to-day to the instructor in elementary geometry, and at least it will suggest to him a few new exercises, the more so since the graphic methods of Porta are not without elegance. But I think Chasles was hardly fair in quoting Porta, for the only part of this work which relates to the transformation of curves is the reproduction (which is found at the end of the 18th problem of Book I) of a practical method which, according to the author's own statement, is due to the celebrated painter Albert Dürer who uses it to transform a circle into an ellipse by the dilation of the ordinates.

The second book of Porta's work is very much less important. Its purpose is to show how one can square areas having curved boundaries. These areas are however made up so as to be readily transformed into areas bounded by straight lines. In fact they are obtained by repeating several times operations of the following type: Consider an area bounded by straight lines and having two sides equal. On these two sides are constructed equal segments having as boundaries arcs of curves. If then one segment is added to the given area and the other subtracted, the resultant area will be equivalent to the initial area. This therefore is an area which can be squared. Such matters are, however, hardly worthy of our consideration.

In his third book Porta comes to the old attempt of Hippocrates of Chios to square the circle by means of lunules (plane areas bounded by two circle arcs). Every one knows that it is impossible to attain the desired end by this method, however alluring it may be. We must consider, however, that Porta devotes less than two of the thirty pages of the book to this celebrated problem, all the rest being given over to an examination of other lunules considered by the ancients, and to areas of other figures of an analogous nature.

The result of all this is that Porta's work has but little importance and no true originality, but it proves that the 
author had a thorough knowledge of the work of Euclid and that he made use of it with remarkable ease. He is therefore a circle squarer of a type different from those met by De Morgan, whose common characteristic is a complete and stubborn ignorance of the science of geometry.

Porta on the contrary knew the classics of the science and was so imbued by the methods of the ancients as to make an evident effort to imitate their procedure and their style. And finally, if we take account of the fact that he lived at a time when geometricians could not walk without the steady support of Euclid and Archimedes, to whose invincible spell they had to submit, we conclude that De Morgan's judgment of Porta is too severe. If indeed we consider him in the large group of authors of paradoxes studied with so much care by the illustrious professor of the University of London, Porta appears - I will not say as a new Archimedes, but at least a monoculus in terra coecorum.

UNIVERSITY OF GENOA, November, 1915.

\section{PIERPONT'S FUNCTIONS OF A COMPLEX VARIABLE.}

Functions of a Complex Variable. By James Pierpont. Ginn and Company, Boston, 1914. xiv + 583 pp. 8vo. Price $\$ 5.00$.

OUT of the general development of higher analysis certain portions have gradually come to be recognized as suitable for introductory material and designated as Theory of Functions, or more precisely, as Functions of a Complex Variable. We have also Functions of a Real Variable, and it might seem as if these should come first; but there is a certain simplicity and elegance about functions of a complex variable that makes their study especially attractive.

In this subject there is much that has been unsettled as to subject matter and method of treatment, and many of the books have quickly become out of date, or have lacked the accuracy now possible. It is therefore a matter of congratulation when a book of this kind comes from the interesting pen of Professor Pierpont. Such a book is bound to have a marked influence on the development of an ideal course. 